\title{
Epidemiology of Pediatric Obstructive Sleep Apnea
}

\author{
Julie C. Lumeng ${ }^{1}$ and Ronald D. Chervin ${ }^{2}$ \\ ${ }^{1}$ Center for Human Growth and Development and Department of Pediatrics, and ${ }^{2}$ Sleep Disorders Center and Department of Neurology, \\ University of Michigan, Ann Arbor, Michigan
}

\begin{abstract}
Pediatric obstructive sleep apnea (OSA) has become widely recognized only in the last few decades as a likely cause of significant morbidity among children. Many of the clinical characteristics of pediatric OSA, and the determinants of its epidemiology, differ from those of adult OSA. We systematically reviewed studies on the epidemiology of conditions considered part of a pediatric sleepdisordered breathing (SDB) continuum, ranging from primary snoring to OSA. We highlight a number of methodologic challenges, including widely variable methodologies for collection of questionnaire data about symptomatology, definitions of habitual snoring, criteria for advancing to further diagnostic testing, and objective diagnostic criteria for SDB or OSA. In the face of these limitations, estimated population prevalences are as follows: parent-reported "always" snoring, 1.5 to 6\%; parent-reported apneic events during sleep, 0.2 to $4 \%$; SDB by varying constellations of parent-reported symptoms on questionnaire, 4 to $11 \%$; OSA diagnosed by varying criteria on diagnostic studies, 1 to $4 \%$. Overall prevalence of parentreported snoring by any definition in meta-analysis was $7.45 \%(95 \%$ confidence interval, 5.75-9.61). A reasonable preponderance of evidence now suggests that SDB is more common among boys than girls, and among children who are heavier than others, with emerging data to suggest a higher prevalence among African Americans. Less convincing data exist to prove differences in prevalence based on age. We conclude by outlining specific future research needs in the epidemiology of pediatric SDB.
\end{abstract}

Keywords: sleep apnea, obstructive; snoring

Accurate identification of the prevalence of primary snoring and obstructive sleep apnea (OSA) in the pediatric population is critical from both a clinical and research perspective. For clinicians, recognizing the prevalence of these conditions and how they vary across the population may prompt more regular, thorough, and targeted screening, and inform clinical decisions about the need for additional diagnostic workup. For researchers, recognizing differences in the prevalence of the disorder between population subgroups may inform the understanding of etiology and guide future investigation. As will be detailed below, the description of sleep-disordered breathing (SDB) prevalence is fraught with difficulty due to a variety of methodologic issues, most of which involve heterogeneity in diagnostic criteria.

\section{DEFINITION}

There is no universally accepted, clear definition of snoring. Thus, prevalence of the condition may differ based on varying perceptions of the word's meaning across cultures. Snoring in

(Received in original form August 22, 2007; accepted in final form October 8, 2007) Supported by the American Heart Association Fellow-to-Faculty Transition Award (no. $0275040 \mathrm{~N}$ ) to J.C.L., and a National Institutes of Health grant (no. HL080941) to R.D.C.

Correspondence and requests for reprints should be addressed to Julie $C$. Lumeng, M.D., Center for Human Growth and Development, 300 North Ingalls Building, 10th Floor, University of Michigan, Ann Arbor, MI 48109-0406. E-mail: jlumeng@umich.edu

Proc Am Thorac Soc Vol 5. pp 242-252, 2008

DOI: $10.1513 /$ pats.200708-135MG

Internet address: www.atsjournals.org
American English is defined as "to breathe during sleep with harsh, snorting noises caused by vibration of the soft palate" (1). In practice, human perception and categorization of the sound is often the gold standard (2). Primary snoring is defined as snoring without associated apneas, hypopneas, hypoxemia, hypercapnia, or sleep fragmentation (3).

The upper airway resistance syndrome (UARS) was first described in 1982 (4) as increasingly negative intrathoracic pressures during inspiration that lead to arousals and sleep fragmentation, in the absence of readily perceived apneas, hypopneas, or oxygen desaturations. Despite the absence of changes in airflow or oxygenation, UARS remains of significant clinical interest given that it has been associated with daytime neurobehavioral symptoms similar to those of OSA, and responds positively to treatment in the same manner as OSA. To our knowledge, the population prevalence of childhood UARS has not been studied and is therefore not included in this article. The most recent revision of the International Classification of Sleep Disorders now lists respiratory event-related arousals as a component of the respiratory disturbance index used to diagnose OSA, so future studies of the epidemiology of OSA may well subsume UARS under the single, broadened diagnostic category.

OSA is defined by the American Thoracic Society (ATS) (5) as "a disorder of breathing during sleep characterized by prolonged partial upper airway obstruction and/or intermittent complete obstruction (obstructive apnea) that disrupts normal ventilation during sleep and normal sleep patterns." Obstructive hypoventilation during sleep is included in the above definition of OSA by the ATS, as it is in the definition given by the International Classification of Sleep Disorders (6). Epidemiologic studies have rarely examined obstructive hypoventilation, which remains unassessed by the ubiquitous apnea-hypopnea index (AHI) and inadequately assessed by most measures of oxygen desaturation. Therefore, in summary, estimates of childhood OSA prevalence may be artificially low because research has often excluded both UARS and obstructive hypoventilation from assessments that were performed.

\section{DIAGNOSIS}

Snoring is frequently associated with OSA, and patients who initially have only primary snoring may be at risk for the future development of OSA with age or weight gain (6). Most (but not all) individuals with OSA have habitual snoring. The vast majority of epidemiologic studies described here, therefore, use a selection method to identify those in the population most likely to have OSA based on clinical symptoms. These clinical symptoms always include snoring, with the additional symptoms used in selection for diagnostic testing varying by study, as will be outlined below. It is important to recognize that the majority of available studies have only performed diagnostic testing on children with habitual snoring. At least some children with OSA have no snoring history reported by their families, and therefore are not identified as OSA cases in the present literature. As a result, the prevalences reported for OSA may be underestimates. 


\section{Questionnaires}

A large number of questionnaires have been used in an attempt to identify snoring and SDB among children. However, in the absence of any universally accepted objective definition of snoring, parental reports of snoring, elicited through variously phrased question items, generally have not been validated against an external gold standard.

One of the first questionnaires, developed by Brouilette and colleagues, generated a "score" to identify cases of OSA, with reportedly high sensitivity and specificity (7). Although used in a number of subsequent studies, as reviewed elsewhere (3), the original high sensitivity and specificity of the score in case identification have not been replicated in several subsequent evaluations. Subsequent work expanding on this instrument, with the addition of other questions (8), did not improve sensitivity or specificity enough to differentiate primary snoring from OSA reliably.

Another difficulty in interpretation of questionnaires on snoring frequency involves the identity of the reporter being someone other than the self, because snoring and other important clues to the presence of OSA occur only during sleep. Several studies among children, particularly with adolescents, have asked for self-report of snoring (9-11). One of these studies did demonstrate that parent and child's self-reports of the child's snoring appear to be well correlated (9), although the actual independence with which the parent and child responded to the questionnaire is not detailed in the report. Parental report of snoring may theoretically be more frequent if the child cosleeps with the parents, and cosleeping prevalence clearly differs across cultures (12). Several groups of investigators have commented on the prevalence of cosleeping in their cohorts and theorized that it may have increased the accuracy of parental report of snoring (13-15). One study actually excluded children who did not sleep in the same room as their parents (16). However, at least three studies have indicated that cosleeping does not affect the prevalence of reported snoring $(13,15,17)$, suggesting that this is not a critical factor to include in studies estimating snoring prevalence.

Few available data address the sensitivity and specificity of the report of "snoring" or other specific symptom items for OSA diagnosed on polysomnography (PSG), although at least one study has shown that a positive response to at least onethird of 22 SDB-related questions had a sensitivity of 0.85 and specificity of 0.87 (18). At present, very few studies perform any diagnostic testing without using snoring as a selection criterion (19-22). In what may be the only study to have used full sleep laboratory-based PSG, among 39 children identified by questionnaire as either not snoring or snoring only rarely, 2 (5\%) had OSA (19). In a study using home cardiorespiratory monitoring during sleep, "loud snoring at least 1 to 2 times per week" was not present in 25 to $47 \%$ of children diagnosed with OSA (20). Among 130 children undergoing overnight in-home monitoring, of those reported by parents to snore only occasionally or never, $3(2.3 \%)$ had "pathologic" snoring on audiotaped recording and $8(6.2 \%)$ had abnormal oxygenation (21). Finally, of 18 adolescents with evidence of OSA on a home cardiorespiratory sleep study, 16 did not have symptoms highly suggestive of OSA, such as snoring, apnea, or daytime sleepiness (22). In summary, to establish symptom-based screening thresholds, more studies are needed that do not use habitual snoring as a requirement to select a child for PSG.

Finally, as will be detailed below, no epidemiologic study has used parent-reported observed apnea alone for either diagnosis of OSA or as a criterion for further diagnostic workup with PSG. The frequency of parent-reported apnea is exceedingly low, and would likely result in many missed cases of OSA if used as a sole diagnostic or screening criterion.

\section{PSG and Other Diagnostic Testing}

Questionnaires and clinical history alone are helpful but not adequate in clinical practice to distinguish childhood primary snoring from OSA (8), and therefore additional diagnostic testing is needed (3). This recommendation is based on the assumption that primary snoring does not carry significant morbidity, an assumption that recent evidence repeatedly challenges (19, 23-28). Nocturnal sleep laboratory-based PSG is considered the gold standard for the diagnosis and assessment of OSA in children and is defined in this article as testing that includes cardiorespiratory monitoring, as well as electroencephalographic, electrooculographic, and electromyographic monitoring. Testing without all of these components is referred to here as cardiorespiratory monitoring. Although PSG is discussed in greater detail in a separate article in this symposium (85), we briefly review the use of PSG to diagnose OSA because some understanding of these methods as applied in the recent past is required to interpret epidemiologic findings generated during this time.

Obstructive apneas and hypopneas recorded on PSG are most frequently summarized by the AHI, which represents the average number of such events per hour of sleep. Diagnostic criteria for OSA among adults are typically the product of expert consensus and often include an AHI of 5 or greater on nocturnal PSG and evidence of disturbed or unrefreshing sleep, daytime sleepiness, or other daytime symptoms. AHI cut points of 5, 15, and 30 events/hour have been suggested to indicate mild, moderate, and severe levels of OSA (29). Recent recommendations suggest inclusion of respiratory event-related arousals, in addition to apneas and hypopneas, in a respiratory disturbance index (RDI) $(29,30)$. The rationale for specific AHI diagnostic criteria in children, in comparison to adults, suffers from less available data and perhaps more heterogeneity across studies. Part of the problem is that few studies have been performed to link specified levels of pediatric OSA with adverse outcomes. At present, an AHI or RDI of 1 to 5 events per hour is most often used in research to identify children with OSA. Varied definitions, as shown in Table 6, have been used in the studies discussed below. Other indices used to characterize OSA include the oxygen desaturation index. The test-retest reliability of one night of PSG is considered adequate in children for diagnosis of OSA $(31,32)$.

Given the expense and limited availability in many communities of overnight in-laboratory PSG, substantial efforts have been made to explore other ways to diagnose OSA. Approaches have included in-home overnight audiotaping, videotaping, pulse oximetry, cardiorespiratory studies, and full in-home PSG. As reviewed elsewhere (3), the validity of each of these methods in children, in comparison to the gold standard of overnight inlaboratory PSG, remains uncertain in the absence of sufficient data.

\section{LITERATURE REVIEW METHODS}

A literature search of the Ovid Medline database for search terms "snoring"; "sleep apnea, obstructive"; "sleep-disordered breathing"; and "sleep apnea syndromes" was undertaken for the years 1950 to May 2007 and limited to articles in the English language and with a population aged 0 to 18 years. This search produced 2,541 articles. Therefore, the search terms "prevalence" and "epidemiology" were added. This produced 127 articles. Abstracts of these articles were reviewed and 51 identified as original research articles evaluating the frequency of snoring, 
OSA, or SDB in a cohort that included children. We excluded articles that studied children with diagnosed OSA or SDB and compared them with a matched control group without the disorder. Of these 51 articles, 38 used community or general pediatric samples. The remaining 13 studies focused on specific populations that were not representative of the general population, leaving 38 studies for review. The bibliographies of recent review articles $(33,34)$ were also compared with results of the automated literature search. Over the course of review, an additional 10 relevant articles were identified. Thus, this review includes 48 original research studies.

\section{OVERVIEW OF STUDY CHARACTERISTICS}

Of the 48 studies, nearly all (46 studies) included questionnaires about sleep-related behaviors. A variety of questionnaires (or modified versions of them) were identified as being used, including the Sleep Disturbance Scale for Children (35), Obstructive Sleep Apnea Questionnaire $(7,36,37)$, Tucson Children's Assessment of Sleep Apnea Screening Questionnaire (38), Sleep Center of Sydney Children's Hospital "epidemiology survey" (39), Children's Sleep Questionnaire (20), American Thoracic Society Questionnaire (14, 16, 21, 40-42), Children's Sleep Habits Questionnaire (43), Pediatric Sleep Questionnaire (44), "a previously validated questionnaire" (45), and unnamed questionnaires designed by Brouilette (46), Ali (13, 47, 48), and Gozal (19). These questionnaires, though often used repeatedly, have widely varying information regarding reliability and validity. The vast majority of studies used questions or a questionnaire specific to the individual study, therefore limiting comparability and suggesting limited evidence for reliability and validity.

The manner in which questions about snoring were asked was also extremely diverse. Studies asked about snoring in reference to the past 24 hours (49), 1 week (38), 1 month (20), 6 months $(17,35,50,51)$, or 12 months (39), but most appeared to give no specific time frame. Some questionnaires specified "loud" snoring $(9,19,20,35,43,45,47,51,52)$ and some included questions about "snorting" $(9,35,53)$. A number of studies did not describe how the question about snoring was asked $(10,15,20$, $39,54-58)$, defined snoring only dichotomously $(10,15,20,39$, $49,53-57,59)$, or did not report the specific prevalence of snoring in any manner (42-44). A number of studies asked about frequency of snoring using a Likert scale, but its use varied dramatically by study (Table 1 ), such that comparisons across studies are very difficult. The use of terms such as "often," "frequently," "rarely," "sometimes," "seldom," and "occasionally" was common across scales, but when numeric values for these terms were specified, there was significant variability in their meaning. For example, in some studies, "rarely" meant "once per week" $(19,51)$, whereas in others, it meant "a few times ever"(9). "Often" meant anywhere from " 3 to 5 times per week" (35) to "at least once per week" (9). Likewise, the definition of a "habitual snorer" varied significantly (Table 2). Future research would benefit from some standardization of the manner in which snoring frequency is quantified across studies.

Finally, the vast majority of studies reviewed here were drawn from community samples, primarily schools. However, several studies drew subjects from general pediatric practices or outpatient clinics. Methods included mailed questionnaires (51), selection at random from a general pediatric practice list (60), interviews in a general pediatric practice waiting room (44), and interviews in a hospital's outpatient clinic waiting rooms (57). Children in the waiting room of a general pediatric clinic presenting for specific types of problems, including neurologic and noninfectious respiratory conditions, more commonly report symptoms of SDB as compared with children presenting for a well-child exam (44). This observation highlights the importance of estimating population prevalence based on community samples as opposed to estimations based on those presenting in medical settings.

\section{PREVALENCE OF SDB}

\section{Parent-reported Snoring Prevalence}

Table 3 and Figure 1 show the prevalence of snoring as reported by parents, sorted by the study-specific definition that each report used. As can be seen, a number of studies used the definition "always," and these studies, not surprisingly, generally had the lowest reported prevalence of snoring, in the range of 1.5 to $6.2 \%$. For comparison, studies using the definition "often" had a range of 3.2 to $14.8 \%$, with one outlier at $34.5 \%$. When snoring was defined as simply a "yes or no" question, as the last few studies on the chart illustrate, snoring prevalence rates were highly variable, illustrating the need to specify a frequency when gathering a snoring history. We performed a meta-analysis using generalized estimating equations to adjust for overdispersion resulting from heterogeneity of the results of

TABLE 1. POTENTIAL RESPONSES FOR FREQUENCY OF SNORING IN STUDIES USING LIKERT SCALES

\begin{tabular}{|c|c|c|c|c|c|}
\hline \multicolumn{6}{|c|}{ Likert Options* } \\
\hline Never (35) & & Occasionally: $\leqslant 1-2 \times / \mathrm{mo}$ & Sometimes: $1-2 \times / w k$ & Often: $3-5 \times / w k$ & Always \\
\hline Never $(19,51)$ & Rarely: $1 \times /$ wk & Occasionally: $2 \times / w k$ & & Frequently: $3-4 \times / w k$ & Almost always: $>4 \times / w k$ \\
\hline Never (9) & Rarely: "few times ever" & Sometimes: few nights/mo & & Often: $\geqslant 1 \times / w k$ & $\begin{array}{l}\text { Very often: almost } \\
\text { every night }\end{array}$ \\
\hline Never (65) & Seldom: $\leqslant 1 \times /$ wk & Sometimes: $2 \times / w k$ & & & Always: $\geqslant 3 \times / w k$ \\
\hline Never (38) & & & $1-2 \times / w k$ & $3-5 \times / w k$ & $6-7 \times / w k$ \\
\hline Never (50) & Only with colds & $<1 \times /$ wk & $\geqslant 1 \times / w k$ & & Every night \\
\hline Never (71) & & & $1-2 \times / w k$ & $3-4 \times / w k$ & Every night \\
\hline Never (17) & & Occasionally & $1-2 \times / w k$ & $3-4 \times / w k$ & $\geqslant 5 \times / \mathrm{wk}$ \\
\hline Never (22) & Rarely: $\leqslant 1 \times /$ wk & Sometimes: $2 \times / w k$ & & Often: $\geqslant 3 \times / w k$ & \\
\hline Never (36) & Seldom & & & Often & Always \\
\hline $\begin{array}{l}\text { Never }(13,14,16,40,47 \\
\quad 48,60,66)\end{array}$ & Rarely/only with colds & Occasionally/Sometimes & & Often/most nights & \\
\hline Never $(46,52)$ & Rarely & Occasionally & & Frequently & Always/almost always \\
\hline Never $(11,21,37,45,69,83)$ & & Occasionally/sometimes & & Often/frequently & Always \\
\hline Never (41) & Seldom & Sometimes & & Often & Very often \\
\hline Never (64) & Seldom & Sometimes & & & Always \\
\hline
\end{tabular}

\footnotetext{
* Likert options range from "never" (left side of table) to "always" (right side of table).
} 
TABLE 2. DEFINITIONS OF "HABITUAL SNORING" OR A "SNORER"

Definition

$1-2 \times /$ wk $(20)$

$\geqslant 3 \times /$ wk $(65,71)$

$>3 \times /$ wk (69)

Snoring more than half the time while asleep (44)

Often/frequently $(11,14,16,21,36,37,40,41,45,46)$

Most nights $(13,47,48,66)$

$>4 \times /$ wk (55)

$\geqslant 4 \times / \mathrm{wk}(56)$

$\geqslant$ Every other night (57)

$6-7 \times /$ wk (38)

Every night $(50,64,83)$

Study reference numbers are shown in parentheses in the first column.

the studies, and found a prevalence of $7.45 \%$ (95\% confidence interval, 5.75-9.61).

\section{Parent-reported Apnea Prevalence}

Table 4 shows the 21 studies reporting the prevalence of parentreported apneic events during sleep. As can be seen, the definitions used to describe an apneic event across studies varied

TABLE 3. PREVALENCE OF HABITUAL SNORING BY DEFINITION

\begin{tabular}{|c|c|c|c|c|}
\hline Definition & No. & Location & Age range & Prevalence \\
\hline \multirow[t]{4}{*}{ Always } & 3,680 & Greece (50) & $1-18 \mathrm{yr}$ & 4.2 \\
\hline & 1,211 & Turkey (83) & $6-13 \mathrm{yr}$ & 2.4 \\
\hline & 895 & Italy (64) & $3-11 \mathrm{yr}$ & 4.9 \\
\hline & 325 & Sweden (58) & $4 \mathrm{yr}$ & 6.2 \\
\hline Almost always & 1,014 & United States (9) & $13-16 \mathrm{yr}$ & 6.0 \\
\hline$\geqslant 6 \times / w k$ & 3,047 & Hong Kong (38) & $6-12 \mathrm{yr}$ & 10.9 \\
\hline$>4 \times / \mathrm{wk}$ & 985 & Australia (55) & $4-12 \mathrm{yr}$ & 15.2 \\
\hline$\geqslant 4 \times / \mathrm{wk}$ & 974 & Australia (56) & $2-5 \mathrm{yr}$ & 10.5 \\
\hline$\geqslant$ Every other night & 200 & Singapore (57) & $6.4 \pm 4 \mathrm{yr}$ & 14.5 \\
\hline \multirow[t]{4}{*}{ Most nights } & 1,008 & Thailand (13) & $6-13 \mathrm{yr}$ & 8.5 \\
\hline & 782 & United Kingdom (47) & $4-5 \mathrm{yr}$ & 12.1 \\
\hline & 782 & United Kingdom (48) & $4-5 \mathrm{yr}$ & 11.4 \\
\hline & 755 & Thailand (66) & $9-10 \mathrm{yr}$ & 6.9 \\
\hline$>$ Half the time & 1,038 & United States (44) & $2.0-13.9 \mathrm{yr}$ & 17.1 \\
\hline \multirow[t]{2}{*}{$>3 \times / \mathrm{wk}$} & 10,279 & Singapore (69) & $4-7 \mathrm{yr}$ & 6.0 \\
\hline & 1,198 & Turkey (65) & $3-11 \mathrm{yr}$ & 3.3 \\
\hline \multirow[t]{5}{*}{$\geqslant 3 \times / \mathrm{wk}$} & 5,728 & United States (19) & $5-7 \mathrm{yr}$ & 11.7 \\
\hline & 3,871 & Korea (71) & $15-18 \mathrm{yr}$ & 11.2 \\
\hline & 2,900 & $\operatorname{Iran}(54)$ & $11-17 \mathrm{yr}$ & 7.9 \\
\hline & 1,844 & Sweden(17) & $5-7 \mathrm{yr}$ & 7.5 \\
\hline & 944 & United States (51) & $2 \mathrm{wk}-2 \mathrm{yr}$ & 5.3 \\
\hline \multirow[t]{9}{*}{ Often } & 25,703 & France (11) & $17-20 \mathrm{yr}$ & 4.6 \\
\hline & 2,209 & Italy (40) & $10-15 \mathrm{yr}$ & 5.6 \\
\hline & 2,147 & Turkey (37) & $5-13 \mathrm{yr}$ & 7.0 \\
\hline & 1,784 & Turkey (36) & $4-17 \mathrm{yr}$ & 4.1 \\
\hline & 1,615 & Italy (16) & $6-13 \mathrm{yr}$ & 7.3 \\
\hline & 454 & Iceland (41) & $6 \mathrm{mo}-6 \mathrm{yr}$ & 3.2 \\
\hline & 447 & Italy (21) & $3-6 \mathrm{yr}$ & 34.5 \\
\hline & 190 & France (14) & $5-6 \mathrm{yr}$ & 10.0 \\
\hline & 100 & Spain (22) & $12-16 \mathrm{yr}$ & 14.8 \\
\hline \multirow[t]{3}{*}{ Frequently } & 1,494 & United States (52) & $4-11 \mathrm{yr}$ & 10.5 \\
\hline & 1,144 & Germany (46) & $9.6 \pm 0.7 \mathrm{yr}$ & 10.1 \\
\hline & 976 & Portugal (45) & $6-11 \mathrm{yr}$ & 8.8 \\
\hline Sometimes & 245 & United Kingdom (60) & $0-10 \mathrm{yr}$ & 27.0 \\
\hline$\geqslant 1 \times / \mathrm{wk}$ & 850 & United States (20) & $8-11 \mathrm{yr}$ & 17.0 \\
\hline Yes/no (loudly) & 3,045 & Belgium (35) & $6-13 \mathrm{yr}$ & 2.5 \\
\hline \multirow[t]{2}{*}{ Yes/no } & 1,650 & Australia (53) & $0-17 \mathrm{yr}$ & 14.2 \\
\hline & 200 & Russia (15) & $2-4 \mathrm{mo}$ & 5.0 \\
\hline \multirow[t]{3}{*}{ Yes/no (last 2 wk) } & 1,585 & New Zealand (59) & $1-6 \mathrm{mo}$ & 26.1 \\
\hline & 179 & Taiwan (10) & $10-19 \mathrm{yr}$ & 26.3 \\
\hline & 141 & United States (49) & $4-8 \mathrm{mo}$ & 12.0 \\
\hline NA & 5,979 & China (39) & $2-12 \mathrm{yr}$ & 5.6 \\
\hline
\end{tabular}

Study reference numbers are shown in parentheses. NA = not available.

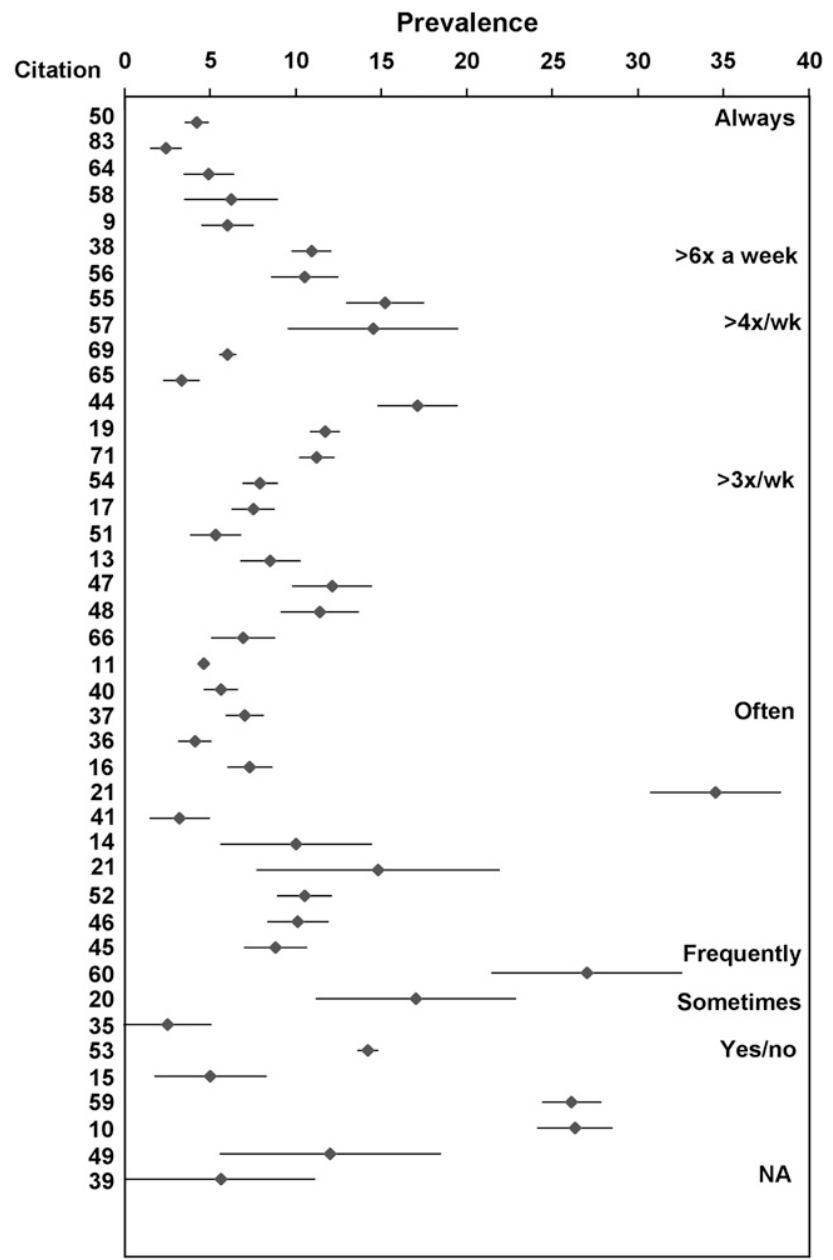

Figure 1. Prevalence (\%) (95\% confidence intervals) of habitual snoring reported across 41 studies reporting questionnaire data for snoring prevalence. Definitions of "habitual snoring" used for each group of studies listed on right-hand side. NA = not available.

widely in both specificity and severity. Most studies support a prevalence of between 0.2 and $4.0 \%$ for relatively similar definitions. One study showed a prevalence of $18.6 \%$ for "breathing cessation" (21). This same study was similarly an outlier for the prevalence of reported habitual snoring (34.5\%) (21), for reasons that remain unclear.

\section{Parent-reported SDB Prevalence}

Although prior reviews have noted that diagnosis of SDB in any particular patient by history alone is highly problematic (3), three studies have attempted to estimate SDB prevalence on the basis of a diagnosis made by history. All samples included more than 1,000 children each, ranging in age collectively from 2 to 16 years, and drawn from Belgium (35) and the United States $(9,44)$. The largest study reported a prevalence of $4.1 \%$ based on the presence of one of five symptoms (35). When SDB was defined as "the report of loud snoring, gasping/choking or snorting, awakening with gasping or choking, or momentary periods of stopped or abnormal breathing occurring weekly," prevalence was reported at $6 \%$ (9). Finally, the prevalence was reported to be $11.1 \%$ when SDB was defined as a positive response to at least one-third of 22 SDB symptoms on the Pediatric Sleep Questionnaire; this criterion previously had proven optimal to distinguish PSG-positive, sleep center-referred children from patients in general pediatric clinic waiting rooms (44). 
TABLE 4. PREVALENCE OF PARENT-REPORTED APNEA

\begin{tabular}{|c|c|c|c|c|}
\hline No. & Location & Age & Definition of Apnea & Prevalence (\%) \\
\hline 10,279 & Singapore (69) & $4-7 \mathrm{yr}$ & Child stops breathing for short periods during sleep (yes/no) & 1.2 \\
\hline 5,979 & China (39) & $2-12 \mathrm{yr}$ & Breathing pauses & 0.2 \\
\hline 3,871 & Korea (71) & $15-18 \mathrm{yr}$ & Breathing cessation during sleep $\geqslant 4 \times / \mathrm{wk}$ & 0.9 \\
\hline 3,680 & Greece (50) & $1-18 \mathrm{yr}$ & Child stops breathing during sleep every night & 1.0 \\
\hline 3,047 & Hong Kong (38) & $6-12 \mathrm{yr}$ & Child stops breathing for a few seconds or struggles to breathe & 1.5 \\
\hline 3,045 & Belgium (35) & $6-13 \mathrm{yr}$ & Child gasps for breath or is unable to breathe during sleep & 0.8 \\
\hline 2,900 & $\operatorname{Iran}(54)$ & $11-17 \mathrm{yr}$ & Apnea (unclear how defined) & 0.4 \\
\hline 2,147 & Turkey (37) & $5-13 \mathrm{yr}$ & Apnea (unclear how defined) & 5.6 \\
\hline 1,784 & Turkey (36) & $4-17 \mathrm{yr}$ & Apnea "often" or "always" & 0.9 \\
\hline 1,494 & United States (52) & 4-11 yr & $\begin{array}{l}\text { Child stops or struggles to breathe, child's lips turned blue, } \\
\text { or parent shook child because they were worried about their } \\
\text { child's breathing during sleep "frequently" or more }\end{array}$ & 3.8 \\
\hline 1,211 & Turkey (83) & $6-13 \mathrm{yr}$ & Apnea "often" or "always" & 1.6 \\
\hline 1,198 & Turkey (65) & $3-11 \mathrm{yr}$ & Child ceases breathing during sleep & 3.3 \\
\hline 1,014 & United States (9) & $13-16 y r$ & $\begin{array}{l}\text { Child stops breathing or breathes abnormally every or } \\
\text { almost every night }\end{array}$ & 0.4 \\
\hline 895 & Italy (64) & $3-11 \mathrm{yr}$ & Child has apnea during sleep & 2.8 \\
\hline 494 & United States (43) & $4-11 \mathrm{yr}$ & Child seems to stop breathing during sleep & 1.7 \\
\hline 454 & Iceland (41) & $6 \mathrm{mo}-6 \mathrm{yr}$ & Apnea often and very often & 1.6 \\
\hline 447 & Italy (21) & $3-6 \mathrm{yr}$ & Breathing cessation & 18.6 \\
\hline 325 & Sweden (58) & $4 \mathrm{yr}$ & Apnea every night & 1.5 \\
\hline 245 & United Kingdom (60) & $0-10 \mathrm{yr}$ & $\begin{array}{l}\text { Child appears to hold breath for short periods of time during } \\
\text { sleep sometimes or often }\end{array}$ & 4.0 \\
\hline 141 & United States (49) & $4-8 \mathrm{mo}$ & Difficult or labored breathing during sleep & 3.0 \\
\hline 101 & Spain (22) & $12-16 \mathrm{yr}$ & Witnessed apnea ever & 2.9 \\
\hline
\end{tabular}

Study reference numbers are shown in parentheses.

In summary, the few available studies found, with relative consistency, a reported SDB prevalence of 4 to $11 \%$.

\section{Prevalence of SDB Diagnosed with Additional Diagnostic Testing}

Of the 46 studies that used questionnaires, 9 aimed to subsequently perform diagnostic testing on all participants (19-22, 42, 46, 61-63). These tests included complete in-hospital overnight PSG $(19,62,63)$, unattended in-home overnight PSG (61), in-home or laboratory-based overnight recording of cardiorespiratory variables but not sleep (20-22, 42), and in-home overnight pulse oximetry (46). Ten studies used widely varying selection criteria from questionnaires or screening tests to identify subjects for further testing $(13,41,46,47,50,57,58$, 64-66) (Table 5). As a result of the varying selection criteria, the proportion of children identified for further diagnostic testing varied significantly.

For example, the proportion of the original sample that was deemed eligible to advance to additional testing on the basis of questionnaire data was $6.2 \%(58), 4.9 \%(64), 3.3 \%(65), 8.3 \%$ (50), 14.5\% (57), 8.4\% (13, 66), 10.9\% (46), 4.0\% (41), and $9.3 \%$ (47). Not all subjects eligible for further study actually participated, and participation rates ranged from $55.2 \%$ (57) to $90.4 \%$ (13). Of the children who had further diagnostic testing, the prevalences within these groups of those with diagnosed OSA (by the respective criteria) were also widely variable: 9 of

\section{TABLE 5. CRITERIA TO ADVANCE TO FURTHER DIAGNOSTIC TESTING FOR OBSTRUCTIVE SLEEP APNEA}

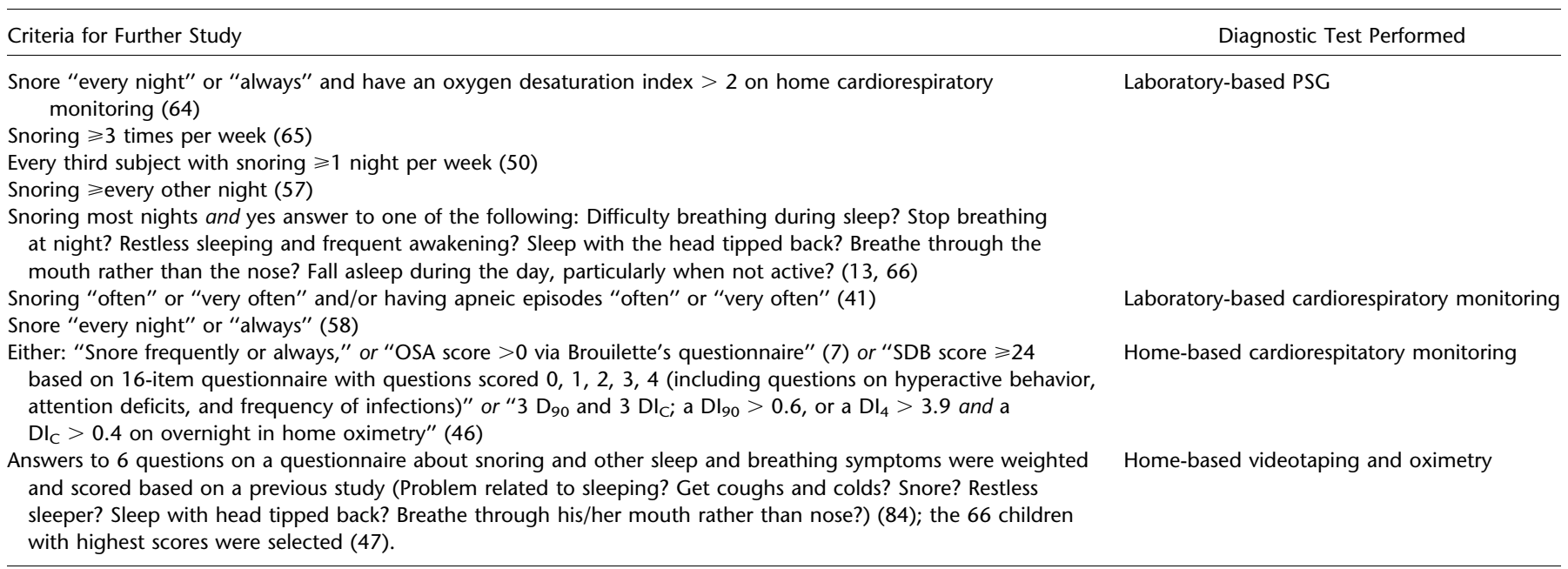

Definition of abbreviations: $\mathrm{DI}=$ desaturation index defined as number of desaturations per hour; $\mathrm{DI}_{4}=$ number of decreases in $\mathrm{SpO}_{2} \geqslant 4 \%$ of baseline per hour; $\mathrm{DI}_{\mathrm{C}}=$

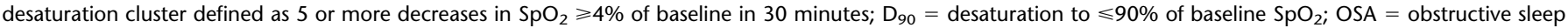
apnea; SDB = sleep-disordered breathing.

Study reference numbers are shown in parentheses. 
12 (64), 11 of 28 (65), 32 of $70(50), 2$ of 16 (57), 7 of 8 (13), 7 of 125 (46), 8 of 11 (41), and 7 of 66 (47) children.

With these limitations in mind, Table 6 shows the prevalence of OSA reported after diagnostic testing in 13 studies. Of these 13 studies, 9 used the AHI, with thresholds varying from 10 to $1(13,19,20,42,50,57,64-66)$ and definitions of hypopneas, if not apneas, likely to have introduced additional variability that is difficult to take into account. One study used the similar RDI, with a threshold of 10 (22). Two used the oxygen desaturation index $(21,41)$, and one used a combination of oxygenation criteria and observation on video without any of the strict definitions outlined above (47). In combination, these studies reported a wide range of prevalence estimates for pediatric OSA, from 0.1 to $13.0 \%$, although most studies suggest a prevalence of 1 to $4 \%$. Clearly, additional work in this area is needed and standardization of selection and diagnostic criteria across studies would be helpful.

Several studies used varying monitoring techniques to examine the prevalence of obstructive or apneic events among normally developing infants. All such studies had samples of more than 500 infants, and, collectively, the ages investigated ranged from several days to 28 weeks. All studies documented that the frequency of obstructive or mixed apneas among apparently normally developing infants is high, ranging from $46.7 \%$ (having either obstructive or mixed apneas) (67), to $44.0 \%$ (having obstructive apneas) (62), to $10.3 \%$ (having more than $1.2 \mathrm{ob}-$ structive apneas per hour) (63). Little is presently known about the precise natural history of these events from infancy into later childhood.

\section{DIFFERENCES IN SDB PREVALENCE BY DEMOGRAHPIC AND ANTHROPOMETRIC FACTORS}

\section{Race}

Our review identified only six studies that have examined a potential association between race or ethnicity and the prevalence of snoring or SDB among children. Four studies found AfricanAmerican race, as compared with white race, to be a significant independent risk factor for $\operatorname{SDB}(9,20,42,51)$. The parents of Hispanic children may describe snoring or apnea more often than the parents of white children (52), but no significant difference in mean RDI has been identified among Hispanic versus white children (68). A study from Singapore reported a higher prevalence of habitual snoring among Malay, as opposed to Chinese or Indian subjects (69). A review of Tables 3, 4, and 6 does not suggest clear differences in the prevalence of snoring, apnea, or OSA in studies coming from different countries (and therefore different ethnic groups). Additional work is needed in this area.

\section{Sex}

We found evidence for a significant difference in the prevalence of snoring or SDB by sex as reviewed in Table 7. Fifteen studies reported a higher prevalence of SDB symptoms among boys, and 19 found no difference by sex. Just a single study reported a higher prevalence of snoring in girls (17). The studies that found a higher prevalence of SDB symptoms among boys had a significantly larger sample size than those that found no difference $($ mean $=4,424[\mathrm{SD}, 6,177]$ vs. mean $=721$ [SD, 467], $P<0.05$ ). Some have proposed that differences in SDB or snoring by sex are more likely to emerge as children enter puberty (when hormonal differences develop that are hypothesized to contribute to the difference in prevalence between adult men and women), and examination of Table 7 suggests a pattern of age as a mediator of the sex difference. Specifically, of the 15 studies that demonstrated a higher prevalence of SDB or snoring among boys, 8 included children aged 13 years or older. In comparison, of the 19 studies that did not demonstrate a higher prevalence of SDB or snoring among boys, only 3 included children aged 13 years or older. Every study that included boys aged 17 years or older found a sex-based difference. One study that examined both age and sex found a significantly higher prevalence of snoring specifically among 11- to 13-yearold boys, compared with girls and boys ages 5 to 10 years (37). Nonetheless, it remains remarkable that more than half of the studies that found a higher prevalence of SDB or snoring among boys did so using cohorts of prepubertal boys. Puberty-related hormonal or physiologic changes may potentiate the effect of sex on SDB or snoring prevalence, but cannot be the sole mechanism responsible for the differences. In summary, we conclude that the prevalence of childhood SDB probably does differ by sex, with boys being affected at rates that are 50 to $100 \%$ higher than those for girls. When these differences are not found, the reason in some cases may be due to inadequate sample size and power to detect a difference.

\section{Age}

Multiple studies have examined within their own cohorts whether symptoms of SDB vary with age. There was no difference in parental report of SDB symptoms by age within the following age windows: 2 to 4 months (15), 2 weeks to 2 years (51), 11 to 17 years (54), 1 to 18 years (50), 2 to 5 years (56), 3 to 6 years (21),

TABLE 6. DEFINITION OF OBSTRUCTIVE SLEEP APNEA ON DIAGNOSTIC TESTING AND ESTIMATED POPULATION PREVALENCE

\begin{tabular}{|c|c|c|c|c|}
\hline Criteria for OSA Diagnosis & Location & No. & Age & Prevalence (\%) \\
\hline $\mathrm{AHI} \geqslant 10$ & United States (42) & 126 & $2-18 \mathrm{yr}$ & 1.6 \\
\hline $\mathrm{RDI} \geqslant 10$ & Spain (22) & 100 & $12-16 \mathrm{yr}$ & 2.0 \\
\hline $\mathrm{AHI} \geqslant 5$ or apnea index $\geqslant 1$ & Greece (50) & 3,680 & $1-18 \mathrm{yr}$ & 4.3 \\
\hline $\mathrm{AHI} \geqslant 5$ & United States (19) & 5,728 & $5-7 \mathrm{yr}$ & 5.7 \\
\hline $\mathrm{AHI} \geqslant 5$ & United States (20) & 850 & $8-11 \mathrm{yr}$ & 2.5 \\
\hline $\mathrm{AHI}>3$ & Italy (64) & 895 & $3-11 \mathrm{yr}$ & 1.0 \\
\hline $\mathrm{AHI}>3$ & Turkey (65) & 1,198 & $3-11 \mathrm{yr}$ & 0.9 \\
\hline $\mathrm{AHI} \geqslant 1$ & Thailand (66) & 755 & $9-10 \mathrm{yr}$ & 1.3 \\
\hline $\mathrm{AHI} \geqslant 1$ & Thailand (13) & 1,008 & $6-13 \mathrm{yr}$ & 0.7 \\
\hline $\mathrm{AHI}>1$ & Singapore (57) & 200 & $6.4 \pm 4 y r$ & 0.1 \\
\hline $\mathrm{ODI} \geqslant 5$ & Italy (21) & 604 & $3-6 y r$ & 13.0 \\
\hline $\mathrm{ODI}>3$ & Iceland (41) & 454 & $6 \mathrm{mo}-6 \mathrm{yr}$ & 2.9 \\
\hline $\begin{array}{l}\text { Upper } 5 \% \text { for nocturnal movement, number of oxygen desaturations, and } \\
\text { pulse rate, with subsequent examination of videos to determine etiology }\end{array}$ & United Kingdom (47) & 782 & $4-5 \mathrm{yr}$ & 0.9 \\
\hline
\end{tabular}

Definition of abbreviations: $\mathrm{AHI}=$ apnea-hypopnea index; RDI = respiratory disturbance index; ODI = oxygen desaturation index.

Study reference numbers are shown in parentheses. 
TABLE 7. PREVALENCE OF SNORING OR SLEEP-DISORDERED BREATHING SYMPTOMS BY SEX

\begin{tabular}{|c|c|c|c|c|c|c|}
\hline \multirow[b]{2}{*}{ No. } & \multirow[b]{2}{*}{ Location } & \multirow[b]{2}{*}{ Snoring or SDB Measure } & \multirow[b]{2}{*}{ Age } & \multicolumn{2}{|c|}{ Prevalence $(\%)$} & \multirow[b]{2}{*}{$P$ Value } \\
\hline & & & & Male & Female & \\
\hline \multicolumn{7}{|c|}{ Studies Showing a Higher Prevalence in Boys } \\
\hline 25,703 & France (11) & Often & $15-20 \mathrm{yr}$ & 6.5 & 3.3 & $<0.001$ \\
\hline 10,279 & Singapore (69) & $>3 \times / w k$ & $4-7 \mathrm{yr}$ & 7.0 & 4.8 & $<0.001$ \\
\hline 5,979 & China (39) & Frequent & $2-12 \mathrm{yr}$ & 6.7 & 4.5 & $<0.001$ \\
\hline 3,871 & Korea (71) & $3 \times / w k$ & $15-18 \mathrm{yr}$ & 12.4 & 8.5 & $<0.001$ \\
\hline 3,680 & Greece (50) & Every night & $1-18 \mathrm{yr}$ & 5.2 & 3.3 & 0.006 \\
\hline 3,047 & Hong Kong (38) & $6-7 \times / \mathrm{wk}$ & $6-12 \mathrm{yr}$ & 13.6 & 7.4 & $<0.001$ \\
\hline 2,900 & Iran (54) & $\geqslant 3 \times / w k$ & $11-17 \mathrm{yr}$ & 12.4 & 4.8 & 0.02 \\
\hline 2,209 & Italy (40) & Often & $10-15 \mathrm{yr}$ & 7.0 & 4.1 & 0.003 \\
\hline 2,147 & Turkey (37) & Often & $5-13 \mathrm{yr}$ & 8.5 & 5.6 & 0.008 \\
\hline 1,650 & Australia (53) & Yes & $0-17 \mathrm{yr}$ & 17.1 & 10.8 & 0.005 \\
\hline 1,585 & New Zealand (59) & Yes (past $2 w k$ or first $4 w k$ of life) & $1-6 \mathrm{mo}$ & 28.9 & 23.0 & 0.01 \\
\hline 1,038 & United States (44) & $\geqslant 3$ of 9 SDB questions positively & $2-13 \mathrm{yr}$ & $\sim 13.0$ & $\sim 9.0$ & $\sim 0.049$ \\
\hline 1,023 & Belgium (67) & Any obstructive apneas on PSG & $2-28 w k$ & 44.5 & 36.0 & 0.006 \\
\hline 755 & Thailand (66) & Most nights & $9-10 \mathrm{yr}$ & 9.4 & 4.7 & 0.003 \\
\hline 494 & United States (43) & Snores loudly, stops breathing, snorts/gasps & $4-11 \mathrm{yr}$ & NA & NA & 0.02 \\
\hline \multicolumn{7}{|c|}{ Studies Showing No Difference in Prevalence by Sex } \\
\hline 1,615 & Italy (16) & Often & $6-13 \mathrm{yr}$ & 15.2 & 16.4 & 0.69 \\
\hline 1,494 & United States (52) & Frequently & $4-11 \mathrm{yr}$ & 11.6 & 9.3 & 0.15 \\
\hline 1,198 & Turkey (65) & $\geqslant 3 \times / \mathrm{wk}$ & $3-11 \mathrm{yr}$ & 3.4 & 3.1 & 0.75 \\
\hline 1,008 & Thailand (13) & Most nights & $6-13 \mathrm{yr}$ & NA & NA & 0.52 \\
\hline 985 & Australia (55) & $>4 \times / w k$ & $4-12 \mathrm{yr}$ & 16.3 & 14.3 & 0.43 \\
\hline 976 & Portugal (45) & Frequently & $6-11 \mathrm{yr}$ & NA & NA & NS \\
\hline 974 & Australia (56) & $4 \times / w k$ & $2-5 \mathrm{yr}$ & 10.5 & 10.5 & 0.99 \\
\hline 944 & United States (51) & $\geqslant 3 \times / \mathrm{wk}$ & $2 \mathrm{wk}-2 \mathrm{yr}$ & NA & NA & NA \\
\hline 895 & Italy (64) & Always & $3-11 \mathrm{yr}$ & 6.1 & 3.7 & 0.12 \\
\hline 850 & United States (20) & Apnea index & $8-11 \mathrm{yr}$ & 3.7 & 5.2 & 0.29 \\
\hline 782 & United Kingdom (47) & Most nights & $4-5 \mathrm{yr}$ & NA & NA & NA \\
\hline 454 & Iceland (41) & Often & $0.5-6 \mathrm{yr}$ & 3.6 & 2.9 & 0.1 \\
\hline 447 & Italy (21) & Often & $2-8 \mathrm{yr}$ & 36.3 & 32.2 & 0.37 \\
\hline 245 & United Kingdom (60) & Sometimes & $0-10 \mathrm{yr}$ & 28.3 & 25.6 & 0.66 \\
\hline 200 & Russia (15) & Yes/no & $2-4 \mathrm{mo}$ & 40.0 & 43.9 & 0.21 \\
\hline 200 & Singapore (57) & $\geqslant$ Every other night & $6 \pm 4 \mathrm{yr}$ & 16.5 & 15.0 & 1.0 \\
\hline 190 & France (14) & Sometimes & $5-6 \mathrm{yr}$ & 9.4 & 10.6 & 0.81 \\
\hline 100 & Spain (22) & Sometimes or often & $12-16 \mathrm{yr}$ & NA & NA & NA \\
\hline 141 & United States (49) & Yes/no (last $24 \mathrm{~h}$ ) & $4-8 \mathrm{mo}$ & NA & NA & NA \\
\hline \multicolumn{7}{|c|}{ Studies Showing a Higher Prevalence in Females } \\
\hline 1,844 & Sweden (17) & $\geqslant 3 \times / w k$ & $5-7 \mathrm{yr}$ & 5.3 & 10.0 & $<0.01$ \\
\hline
\end{tabular}

Definition of abbreviations: NA = not available; NS = not significant; PSG = polysomnography; SDB $=$ sleep $=$ disordered breathing.

Study reference numbers are shown in parentheses.

4 to 11 years $(52,70), 6$ to 11 years $(45), 8$ to 11 years $(20), 2$ to 13 years (44), 12 to 16 years (22), and 15 to 20 years (11). Just four studies have reported a differing prevalence of SDB by age. Snoring prevalence was reported to decrease significantly between ages 4 and 12 years in one study (55). There was no linear increase in snoring prevalence from 9 to 15 years, but there was a significantly higher prevalence among 15 -year-olds than the other age groups in another study (40). In another study, the prevalence of habitual snoring was $7.5 \%$ among 5 - to 8-year-olds, 5.7\% among 9- to 10-year-olds, and $12.9 \%$ among 11 - to 13 -year-olds $(P<0.0001)$ (37). Finally, among infants, the incidence of obstructive or mixed apneas was more common from 2 to 7 weeks than from 8 to 28 weeks of age (67). Comparisons between studies reviewed within this article (Tables 3 , 4 and 6) also do not suggest an obvious pattern of changes in SDB symptom prevalence by age. At present, available data seem insufficient to prove that SDB differs systematically by age.

\section{Weight Status}

In adults, a robust association between obesity and risk of SDB has been described repeatedly. At least 15 studies have investigated the association in children $(9,11,13,15,20-22,40,42$,
$44,53,54,56,69,71)$, but interpretation of the results is complicated by methodologic issues. One of the greatest difficulties is that many studies used parent-reported or self-reported weight and height $(9,11,21,44,71)$, and some did not describe whether weight and height were reported or measured $(15,56)$. Reported weights and heights, as opposed to those that are measured, have been found in recent years to have unacceptably high error rates in adults $(72,73)$, eighth graders (74), high school students (75), and preschoolers (76).

An additional difficulty is the manner in which weight status was identified in many studies. The standard for defining overweight status among children is generally considered to be body mass index (BMI; weight $/$ height $\left.^{2}\left[\mathrm{~kg} / \mathrm{m}^{2}\right]\right)$. The normal distribution of body fat (and BMI) across a population varies by both age and sex, and therefore any measure of BMI must be normed on age- and sex-specific growth charts. For this reason, finite cutoffs for BMI among children in cohorts with a wide range of ages are inappropriate. For example, in one study (42), a finite cutoff of 28 was used as the definition of overweight in a cohort of children aged 2 to 18 years. However, a BMI of 28 is about 5 SDs above the mean in a 4-year-old, and less than 2 SDs above the mean in a 16-year-old. This study found that less than $5 \%$ of its subjects were obese by this definition, which would be signifi- 
cantly below the expected population prevalence. These observations make it difficult to interpret the study's findings of the relationship between obesity and SDB symptoms. Indexing of weight status has also been extremely variable, and studies are therefore difficult to compare. Indexing has included absolute, unnormed BMI $(21,42)$, as well as widely varying, sometimes arbitrary cut points to place children into BMI categories $(9,11$, $40,71)$. Other studies have not used BMI but measures such as ideal body weight for height $(13,22)$, weight alone (15), weightfor-length index (56), and waist-to-hip ratio (22).

Of the 14 studies, 6 reported negative findings $(13,20-22,53$, 56). These 6 studies had sample sizes of 1,650 (53), 974 (56), 850 (20), 447 (21), 255 (13), and 100 (22) subjects, and used unclear methods (56), parent report (21), or measurement $(13,20,22$, 53 ) to index weight status. One study (56) was missing height and weight measurements on a third of its sample, and included all subjects with missing data in the "nonobese" group a priori. Three of the studies $(22,53,56)$ found a somewhat higher prevalence of SDB in the heavier group, but the differences were not statistically significant. Two other studies did not provide any numerical data $(13,21)$. The ages of children in these studies spanned from 0 to 17 years.

Studies that reported significant relationships between a higher categorical weight status and a greater likelihood of SDB are described in Table 8. Five of the eight studies adjusted for potential confounders, including sex $(9,40,69,71)$, race $(9,42,69)$, age $(9,40)$, smoking $(40,69,71)$, and measures of socioeconomic status $(9,40)$. As can be seen in Table 8 , these studies support a relationship between a higher weight status and a greater independent risk of SDB. There is also some evidence for a dose-response relationship in that the odds ratios become greater as the weight status increases. At least one study has shown that the relationship between weight status and SDB is significantly greater in white compared with black adolescents (9), but to our knowledge, the interaction of race and weight status on SDB risk has not been evaluated in any other studies. Despite adjustment for age in two studies listed in Table 8, four of the eight studies had relatively narrow and high age ranges. The single additional study with positive findings not listed in Table 8 demonstrated that infants who were heavier at 2 to 4 months of age had parents who more frequently reported that the infant had noisy breathing or snoring during sleep (15) (the presentation of data in this report did not permit calculation of odds ratios). Available literature may not have tested well, at this point, whether obesity and overweight have different importance among older versus younger children in whom enlarged tonsils are believed to play a major role in SDB risk.

\section{PERSISTENCE, REMITTANCE, AND INCIDENCE}

We performed a separate literature review seeking to identify studies describing the persistence, remittance, and incidence of

TABLE 8. ASSOCIATION BETWEEN SYMPTOMS OF SLEEP-DISORDERED BREATHING AND WEIGHT STATUS IN STUDIES WITH POSITIVE FINDINGS

\begin{tabular}{|c|c|c|c|c|}
\hline No. & Location & Age & Weight Predictor & OR $(95 \% \mathrm{Cl})^{*}$ \\
\hline \multirow[t]{7}{*}{25,703} & \multirow[t]{7}{*}{ France (11) } & \multirow[t]{7}{*}{$17-20 \mathrm{yr}$} & & Often snoring vs. never snoring \\
\hline & & & BMI quintiles $^{\dagger}$ & Boys \\
\hline & & & 1 (low) & 1.00 \\
\hline & & & 2 & $1.20(0.83-1.72)$ \\
\hline & & & 3 & $1.60(1.13-2.27)$ \\
\hline & & & 4 & $1.66(1.18-2.34)$ \\
\hline & & & 5 (high) & $2.62(1.89-3.64)$ \\
\hline \multirow[t]{2}{*}{$3,204^{\ddagger}$} & \multirow[t]{2}{*}{ Singapore (69) } & \multirow[t]{2}{*}{$6-7 \mathrm{yr}$} & $\begin{array}{c}\text { Obese by World Health } \\
\text { Organization criteria }\end{array}$ & $3.75(1.65-8.42)$ \\
\hline & & & Not obese & 1.00 \\
\hline \multirow[t]{3}{*}{3,871} & \multirow[t]{3}{*}{ Korea (71) } & \multirow[t]{3}{*}{$15-18 \mathrm{yr}$} & & Snoring $\geqslant 3 \times /$ wk vs. not snoring \\
\hline & & & $\mathrm{BMI}^{\dagger}<20$ & 1.00 \\
\hline & & & $\mathrm{BMI}^{\dagger}>23$ & $2.61(2.01-3.40)$ \\
\hline \multirow[t]{4}{*}{2,900} & \multirow[t]{4}{*}{$\operatorname{Iran}(54)^{\S}$} & \multirow[t]{4}{*}{$11-17 \mathrm{yr}$} & & Snoring $\geqslant 3 \times /$ wk vs. not snoring \\
\hline & & & $\mathrm{BMI}<85$ th percentile & 1.00 \\
\hline & & & $\mathrm{BMI} \geqslant 85$ th and $<95$ th percentile & 2.10 \\
\hline & & & $\mathrm{BMI} \geqslant 95$ th percentile & 2.40 \\
\hline \multirow[t]{5}{*}{2,209} & \multirow[t]{5}{*}{ Italy (40) } & \multirow[t]{5}{*}{$10-15 \mathrm{yr}$} & & Snoring often vs. not snoring often \\
\hline & & & $\mathrm{BMI}<$ 76th percentile & 1.00 \\
\hline & & & 76-90th percentile & $0.97(0.6-1.6)$ \\
\hline & & & 91-95th percentile & $1.99(1.1-3.5)$ \\
\hline & & & 96-100th percentile & $2.66(1.4-4.9)$ \\
\hline \multirow[t]{3}{*}{1,038} & \multirow[t]{3}{*}{ United States (44) } & \multirow[t]{3}{*}{$2-13 y r$} & & $>$ One-third of 22 SDB questions answered positively \\
\hline & & & Parent report child is overweight ${ }^{\dagger}$ & $3.16(1.66-6.03)$ \\
\hline & & & Parent report child is not overweight & 1.00 \\
\hline \multirow[t]{3}{*}{1,014} & \multirow[t]{3}{*}{ United States (9) } & \multirow[t]{3}{*}{$13-16 \mathrm{yr}$} & & $\begin{array}{l}\text { Affirmative responses to } 5 \text { questions related to } \\
\text { symptoms of loud snoring or any apnea symptoms } \\
\text { occurring at least weekly }\end{array}$ \\
\hline & & & $\mathrm{BMI}^{\dagger}<$ median & 1.00 \\
\hline & & & $\mathrm{BMI}^{\dagger}>$ median (21.5) & $2.57(1.60-4.08)$ \\
\hline \multirow[t]{3}{*}{399} & \multirow[t]{3}{*}{ United States (42) } & \multirow[t]{3}{*}{$2-18 \mathrm{yr}$} & & SDB on PSG vs. no SDB \\
\hline & & & $\mathrm{BMI}<28$ & 1.00 \\
\hline & & & $\mathrm{BMI}>28$ & $4.69(1.59-14.15)$ \\
\hline
\end{tabular}

Definition of abbreviations: $\mathrm{BMI}=$ body mass index; $\mathrm{Cl}=$ confidence interval; PSG = polysomnography; SDB = sleep-disordered breathing.

Study reference numbers are shown in parentheses.

* For relationship of weight status to SDB symptoms.

$\dagger$ Measure of weight is self- or parent-reported, or not described.

¥ Sample size smaller than original study because BMI data available only for subset of sample.

${ }^{\S}$ Inadequate data available to permit calculation of $95 \% \mathrm{Cl}$. 
SDB cases. A significant gap exists in research literature regarding both the incidence of new SDB cases and remittance of existing SDB cases with age. Furthermore, we reviewed no data that address whether the population prevalence of childhood SDB or snoring has increased over time. One might hypothesize this to be the case if SDB is truly more common among children of higher weight status, given that the prevalence of overweight among children has increased dramatically over the past several decades (77). Additional work is needed in this area.

We did find a limited amount of data on incidence and remittance of SDB in individual children within a population. Ali and colleagues evaluated 507 children via questionnaire at 4 to 5 years old (47) and again at ages 6 to 7 years (48). Half of the 60 children who snored "most nights" at the first time point no longer did so at the second time point, but 30 children who had snored less frequently than most nights at the first time point were reported to snore most nights at the second time point, resulting in the same prevalence of habitual snoring $(11.2 \%)$ at both time points. Marcus and coworkers studied a cohort of 20 children with a repeat PSG 1 to 3 years after a diagnosis of primary snoring based on a negative initial PSG (78). All 20 children continued to snore at follow-up, with $80 \%$ snoring "every night." Only 2 of the 20 children were newly diagnosed with OSA on the repeat study, and the OSA was considered mild. Topol and Brooks followed 13 children who had symptoms of OSA, but a negative PSG, with repeat questionnaires and nocturnal studies (laboratory PSG or home cardiorespiratory study) in nine subjects 3 years later (79). Five of 13 parents reported that the child's snoring had improved between the two time points, and four reported it had worsened. There was no significant change in the results of the nocturnal studies in eight of the nine patients. Finally, Anuntaseree and colleagues surveyed the parents of 1,008 first-grade Thai children in 1999, and identified a prevalence of parent-reported habitual snoring ("snoring on most nights") of $8.5 \%$ (13). Eight children underwent laboratory-based PSG (after a selection process outlined in Table 5) and seven were diagnosed with mild OSA (with an AHI $>1$ but less than 5). The majority of this cohort $(\mathrm{n}=755)$ was studied 3 years later in fourth grade (66). At the second time point, $6.9 \%$ of children were described as habitual snorers. Of the 61 habitual snorers at the first time point, 21 continued to snore habitually. In contrast, $12(2.9 \%)$ of the children who never snored at the first time point were reported to snore habitually at the second time point. In total, there were 31 new habitual snorers at the second time point, and five of these were newly diagnosed with OSA. Of six children with OSA diagnosed at the first time point, five continued to snore habitually. All of these children had been diagnosed with mild OSA at the time of the first study and none had undergone treatment. These five children had all developed more severe OSA on PSG at the second study.

At least two other studies have also examined the incidence and remittance of habitual snoring, although not OSA diagnosed by PSG. Urschitz and coworkers found, among more than 1,000 children, that 114 snored habitually ("frequently" or "always") at baseline in the third grade. Of these 114 children, 80 were followed up 1 year later: nearly half (48.8\%) still snored habitually. Three children $(4.2 \%)$ had increased their snoring (e.g., from frequently to always) (80). Chervin and colleagues obtained questionnaire data on 229 children, ages 2 to 13 years, at baseline and 4 years later. Of the 28 children who snored habitually ("more than half the time") at baseline, $44.0 \%$ continued to do so at follow-up 4 years later. Of the 191 children who did not snore habitually at baseline, $4.3 \%$ had begun to snore habitually at follow-up 4 years later (81).

In summary, the few data available suggest the following: (1) children with abnormal findings on PSG are likely to continue to have abnormal findings, if untreated, several years later; (2) a significant proportion of children who habitually snore will have spontaneous resolution of this symptom several years later; and (3) a small proportion of children who do not habitually snore will begin to snore habitually several years later.

\section{CONCLUSIONS}

We have reviewed available evidence to describe the prevalence of SDB among children, differences in prevalence by subject characteristics, and incidence, persistence, and remittance of the condition. Strengths of the current literature include the large sample sizes of questionnaire-based studies and the fact that cohorts have come from all parts of the world, providing information on the international prevalence of the disorders. However, several limitations in available literature are also apparent. Studies may have underestimated OSA prevalence because most did not investigate UARS and obstructive hypoventilation, both of which are now included in definitions of pediatric OSA. Because snoring or other nonubiquitous OSA symptoms have often been used to identify subjects eligible for PSG, additional underestimation of OSA prevalence may have occurred. Whether primary snoring should be included in the list of consequential SDBs is not yet completely clear. Significant heterogeneity exists in the measures and diagnostic criteria that have been used in epidemiologic studies to identify SDB. Complete laboratory-based PSG remains a resource-intensive procedure, and therefore the sample sizes of children studied with PSG have been relatively small.

Within these limitations, review of relevant literature suggests that habitual snoring among children, defined as the most restrictive "always" snoring, has a parent-reported prevalence in the range of 1.5 to $6 \%$. Parent-reported "habitual" snoring is in the range of 5 to $12 \%$. The prevalence of parent-reported apneic events during sleep is in the range of 0.2 to $4 \%$. The prevalence of SDB by varying constellations of parent-reported symptoms on questionnaire is estimated at 4 to $11 \%$. The prevalence of OSA diagnosed by varying criteria on diagnostic studies has ranged widely from 0.1 and $13 \%$, but most studies report a figure between 1 and $4 \%$. Relatively persuasive if not uniform evidence suggests that SDB is more common among boys and among children who are heavier. Available data have not yet proven clear differences in prevalence based on age. Some data do suggest a higher prevalence among AfricanAmerican, compared with white, children in the United States, although differences in prevalence based on race or ethnicity among other populations worldwide remain far less clear.

Additional studies are needed with large sample sizes that will allow more thorough investigation of the following: (1) the sensitivity and specificity of symptoms for a PSG-confirmed diagnosis of OSA, (2) the natural history of PSG-confirmed OSA if not treated, (3) the incidence rates at which new cases of OSA develop across childhood, (4) outcomes that can support evidence-based PSG and alternative diagnostic criteria, and (5) the existence and etiology of differences in SDB prevalence based on sex and weight (which are probably significant) and race and age (which may or may not be significant).

Pediatric SDB may represent a major, as of yet poorly addressed public health burden with many years of potential consequences for affected individuals, their families, and society. In all likelihood, many cases remain undiagnosed, and of those identified, more still remain untreated (82). The morbidity associated with SDB is only beginning to be understood and widely appreciated. Further research into the epidemiology of childhood SDB and its consequences could play a key role in improving efforts to systematically diagnose and treat this condition. 
Conflict of Interest Statement: Neither author has a financial relationship with a commercial entity that has an interest in the subject of this manuscript.

\section{References}

1. American Heritage Dictionary. 4th ed. Boston: Houghton Mifflin; 2001.

2. Strollo PJ, Sanderes MH. Significance and treatment of nonapneic snoring. Sleep 1993;16:403-408.

3. Pediatric Pulmonology Subcommittee on Obstructive Sleep Apnea Syndrome, American Academy of Pediatrics. Clinical practice guideline: diagnosis and management of childhood obstructive sleep apnea syndrome. Pediatrics 2002;109:704-712.

4. Guilleminault C, Winkle R, Korobkin R, Simmons B. Children and nocturnal snoring-evaluation of the effects of sleep related respiratory resistive load and daytime functioning. Eur J Pediatr 1982;139: $165-171$.

5. American Thoracic Society. Standards and indications for cardiopulmonary sleep studies in children. Am J Respir Crit Care Med 1996;153: 866-878.

6. American Academy of Sleep Medicine. International classification of sleep disorders: diagnostic and coding manual. 2nd ed. Westchester, IL: American Academy of Sleep Medicine; 2005.

7. Brouilette R, Hanson D, David R. A diagnostic approach to suspected obstructive sleep apnea in children. J Pediatr 1984;105:10-14.

8. Carroll JL, McColley SA, Marcus CL, Curtis S, Loughlin GM. Inability of clinical history to distinguish primary snoring from obstructive sleep apnea syndrome in children. Chest 1995;108:610-618.

9. Johnson EO, Roth T. An epidemiologic study of sleep-disordered breathing symptoms among adolescents. Sleep 2006;29:1135-1142.

10. Liu SA, Liu CY. Prevalence of snoring in Taichung area: an epidemiological study. J Chin Med Assoc 2004;67:32-36.

11. Delasnerie-Laupretre N, Patois E, Valtax JL, Kauffman F, Alperovitch A. Sleep, snoring, and smoking in high school students. J Sleep Res 1993;2:138-142.

12. Owens JA. Sleep in children: cross-cultural perspectives. Sleep Biol Rhythms 2004;2:165-173.

13. Anuntaseree W, Rookkapan K, Kuasirikul S, Thongsuksai P. Snoring and obstructive sleep apnea in Thai school-age children: prevalence and predisposing factors. Pediatr Pulmonol 2001;32:222-227.

14. Teculescu DB, Caillier I, Perrin P, Rebstock E, Rauch A. Snoring in French preschool children. Pediatr Pulmonol 1992;13:239-244.

15. Kelmanson IA. Snoring, noisy breathing in sleep and daytime behaviour in 2-4-month-old infants. Eur J Pediatr 2000;159:734-739.

16. Corbo GM, Fuciarelli F, Foresi A, De Benedetto F. Snoring in children: association with respiratory symptoms and passive smoking. BMJ 1989; 299:1491-1494.

17. Smedje H, Broman JE, Hetta J. Parents' reports of disturbed sleep in 5-7-year-old Swedish children. Acta Paediatr 1999;88:858-865.

18. Chervin RD, Hedger KM, Dillon JE, Pituch KJ. Pediatric Sleep Questoinnaire (PSQ): validity and reliability of scales for sleepdisordered breathing, snoring, sleepiness, and behavioral problems. Sleep Med 2000;1:21-32.

19. O'Brien LM, Holbrook CR, Mervis CB, Klaus CJ, Bruner JL, Raffield TJ, Rutherford J, Mehl RC, Wang M, Tuell A, et al. Sleep and neurobehavioral characteristics of 5- to 7-year-old children with parentally reported symptoms of attention-deficit/hyperactivity disorder. Pediatrics 2003;111:554-563.

20. Rosen CL, Larkin EK, Kirchner HL, Emancipator JL, Bivins SF, Surovec SA, Martin RJ, Redline S. Prevalence and risk factors for sleep-disordered breathing in 8- to 11-year-old children: association with race and prematurity. $J$ Pediatr 2003;142:383-389.

21. Castronovo V, Zucconi M, Nosetti L, Marazzini C, Hensley M, Veglia F, Nespoli L, Ferini-Strambi L. Prevalence of habitual snoring and sleep-disordered breathing in preschool-aged children in an Italian community. J Pediatr 2003;142:377-382.

22. Sanchez-Armengol A, Fuentes-Pradera MA, Capote-Gill F, Garcia-Diaz E, Cano-Gomez S, Carmona-Bernal C, Castillo-Gomez J. Sleep-related breathing disorders in adolescents aged 12 to 16 years: clinical and polygraphic findings. Chest 2001;119:1393-1400.

23. Chervin RD, Ruzicka DL, Giordani BJ, Weatherly RA, Dillon JE, Hodges EK, Marcus CL, Guire KE. Sleep-disordered breathing, behavior, and cognition in children before and after adenotonsillectomy. Pediatrics 2006;117:e769-e778.

24. Chervin RD, Archbold KH. Hyperactivity and polysomnographic findings in children evaluated for sleep-disordered breathing. Sleep 2001; 24:313-320.
25. Gottlieb DJ, Chase C, Vezina RM, Heeren TC, Corwin MJ, Auerbach SH, Weese-Mayer DE, Lesko SM. Sleep-disordered breathing symptoms are associated with poorer cognitive function in 5-year-old children. J Pediatr 2004;145:458-464.

26. Melendres CS, Lutz JM, Rubin ED, Marcus CL. Daytime sleepiness and hyperactivity in children with suspected sleep-disordered breathing. Pediatrics 2004;114:768-775.

27. Beebe DW, Wells CT, Jeffries J, Chini B, Kalra M, Amin R. Neuropsychological effects of pediatric obstructive sleep apnea. J Int Neuropsychol Soc 2004;10:962-975.

28. Emancipator JL, Storfer-Isser M, Taylor HG, Rosen CL, Kirchner HL, Johnson NL, Zambito AM, Redline S. Variation of cognition and achievement with sleep-disordered breathing in full-term and preterm children. Arch Pediatr Adolesc Med 2006;160:203-210.

29. American Academy of Sleep Medicine Task Force. Sleep-related breathing disorders in adults: recommendations for syndrome definition and measurement techniques in clinical research. Sleep 1999;22:667-689.

30. American Academy of Sleep Medicine. International classification of sleep disorders: diagnostic and coding manual. 2nd ed. Westchester, IL: American Academy of Sleep Medicine; 2005

31. Scholle S, Scholle HC, Kemper A, Glaser S, Rieger B, Kemper G, Zwacka G. First night effect in children and adolescents undergoing polysomnography for sleep-disordered breathing. Clin Neurophysiol 2003;114:2138-2145.

32. Grigg-Damberger M, Gozal D, Marcus CL, Quan SF, Rosen CL, Chervin RD, Wise M, Picchietti DL, Sheldon SH, Iber C. The visual scoring of sleep and arousal in infants and children. J Clin Sleep Med 2007;3:201-240.

33. Schechter MS; Pediatric Pulmonology Subcommittee on Obstructive Sleep Apnea Syndrome. Technical report: diagnosis and management of childhood obstructive sleep apnea syndrome. Pediatrics 2002;109:e69.

34. Young T, Peppard PE, Gottlieb DJ. Epidemiology of obstructive sleep apnea: a population health perspective. Am J Respir Crit Care Med 2002;165:1217-1239.

35. Spruyt K, O'Brien LM, Macmillan Coxon AP, Cluydts R, Verleye G, Ferri R. Multidimensional scaling of pediatric sleep breathing problems and bio-behavioral correlates. Sleep Med 2006;7:269-280.

36. Akcay A, Kara CO, Dagdeviren E, Zencir M. Variation in tonsil size in 4- to 17-year-old schoolchildren. J Otolaryngol 2006;35:270-274.

37. Ersu R, Arman AR, Save D, Karadag B, Karakoc F, Berkem M, Dagli E. Prevalence of snoring and symptoms of sleep-disordered breathing in primary school children in Istanbul. Chest 2004;126:19-24.

38. Ng DK, Kwok KL, Cheung JM, Leung SY, Chow PY, Wong WH, Chan $\mathrm{CH}$, Ho JC. Prevalence of sleep problems in Hong Kong primary school children: a community-based telephone survey. Chest 2005;128: 1315-1323.

39. Liu X, Ma Y, Wang Y, Jiang Q, Rao X, Lu X, Teng H. Brief report: an epidemiologic survey of the prevalence of sleep disorders among children 2 to 12 years old in Beijing, China. Pediatrics 2005;115:266-268.

40. Corbo GM, Forastiere F, Agabiti N, Pistelli R, Dell'Orco V, Perucci CA, Valente S. Snoring in 9- to 15-year-old children: risk factors and clinical relevance. Pediatrics 2001;108:1149-1154.

41. Gislason T, Benediktsdottir B. Snoring, apneic episodes, and nocturnal hypoxemia among children 6 months to 6 years old: an epidemiologic study of lower limit of prevalence. Chest 1995;107:963-966.

42. Redline S, Tishler PV, Schluchter M, Aylor J, Clark K, Graham G. Risk factors for sleep-disordered breathing in children. Am J Respir Crit Care Med 1999;159:1527-1532.

43. Owens JA, Spirito A, McGuinn M, Nobile C. Sleep habits and sleep disturbance in elementary school-aged children. J Dev Behav Pediatr 2000;21:27-36.

44. Archbold KH, Pituch KJ, Panahi P, Chervin RD. Symptoms of sleep disturbances among children at two general pediatric clinics. J Pediatr 2002;140:97-102.

45. Ferreira AM, Clemente V, Gozal D, Gomes A, Pissarra C, Cesar H, Coelho I, Silva CF, Azevedo MH. Snoring in Portuguese primary school children. Pediatrics 2000;106:E64.

46. Schlaud M, Urschitz MS, Urschitz-Duprat PM, Poets CF. The German study on sleep-disordered breathing in primary school children: epidemiological approach, representativeness of study sample, and preliminary screening results. Paediatr Perinat Epidemiol 2004;18:431-440.

47. Ali NJ, Pitson DJ, Stradling JR. Snoring, sleep disturbance, and behavior in 4-5 year-olds. Arch Dis Child 1993;68:360-366.

48. Ali NJ, Pitson D, Stradling JR. Natural history of snoring and related behaviour problems between the ages of 4 and 7 years. Arch Dis Child 1994;71:74-76. 
49. Weissbluth M, Davis AT, Poncher J. Night waking in 4- to 8-month-old infants. J Pediatr 1984;104:477-480.

50. Kaditis AG, Finder J, Alexopoulos EI, Starantzis K, Tanou K, Gampeta S, Agorogiannis E, Christodoulou S, Pantazidou A, Gourgoulianis K, et al. Sleep-disordered breathing in 3,680 Greek children. Pediatr Pulmonol 2004;37:499-509.

51. Montgomery-Downs HE, Gozal D. Sleep habits and risk factors for sleep-disordered breathing in infants and young toddlers in Louisville, Kentucky. Sleep Med 2006;7:211-219.

52. Goodwin JL, Babar SI, Kaemingk KL, Rosen GM, Morgan WJ, Sherrill DL, Quan SF. Symptoms related to sleep-disordered breathing in white and Hispanic children: the Tucson Children's Assessment of Sleep Apnea Study. Chest 2003;124:196-203.

53. Valery PC, Masters IB, Chang AB. Snoring and its association with asthma in indigenous children living in the Torres Strait and Northern Peninsula area. J Paediatr Child Health 2004:40:461-465.

54. Bidad K, Anari S, Aghamohamadi A, Gholami N, Zadhush S, Moaieri H. Prevalence and correlates of snoring in adolescents. Iran J Allergy Asthma Immunol 2006;5:127-132.

55. Zhang G, Spickett J, Rumchev K, Lee AH, Stick S. Snoring in primary school children and domestic environment: a Perth school based study. Respir Res 2004;5:19.

56. Lu LR, Peat JK, Sullivan CE. Snoring in preschool children: prevalence and association with nocturnal cough and asthma. Chest 2003;124: 587-593.

57. Ng DK, Kwok KL, Poon G, Chau KW. Habitual snoring and sleep bruxism in a paediatric outpatient population in Hong Kong. Singapore Med J 2002;43:554-556.

58. Hultcrantz E, Lofstrand-Tidestrom B, Ahlquist-Rastad J. The epidemiology of sleep related breathing disorder in children. Int $J$ Pediatr Otorhinolaryngol 1995;32:S63-S66.

59. Mitchell EA, Thompson JM. Snoring in the first year of life. Acta Paediatr 2003;92:425-429.

60. Owen GO, Canter RJ, Robinson A. Snoring, apnoea and ENT symptoms in the paediatric community. Clin Otolaryngol Allied Sci 1996;21:130-134.

61. Mulvaney SA, Kaemingk KL, Goodwin JL, Quan SF. Parent-rated behavior problems associated with overweight before and after controlling for sleep disordered breathing. BMC Pediatr 2006;6:34.

62. Kahn A, Groswasser J, Sottiaux M, Kelmanson I, Rebuffat E, Franco P, Dramaix M, Wayenberg JL. Prenatal exposure to cigarettes in infants with obstructive sleep apneas. Pediatrics 1994;93:778-783.

63. Kahn A, Growasser J, Sottiaux M, Rebuffat E, Sunseri M, Franco P, Dramaix M, Bochner A, Belhadi B, Foerster M. Clinical symptoms associated with brief obstructive sleep apnea in normal infants. Sleep 1993;16:409-413.

64. Brunetti L, Rana S, Lospalluti ML, Petrafesa A, Francavilla R, Fanelli M, Armenio L. Prevalence of obstructive sleep apnea syndrome in a cohort of 1207 children of southern Italy. Chest 2001;120:1930-1935.

65. Sogut A, Altin R, Uzun L, Ugur MB, Tomac N, Acun C, Kart L, Can G. Prevalence of obstructive sleep apnea syndrome and associated symptoms in 3-11-year-old Turkish children. Pediatr Pulmonol 2005; 39:251-256.
66. Anuntaseree W, Kuasirikul S, Suntornlohanakul S. Natural history of snoring and obstructive sleep apnea in Thai school-age children. Pediatr Pulmonol 2005;39:415-420.

67. Kato I, Franco P, Groswasser J, Kelmanson I, Togari H, Kahn A. Frequency of obstructive and mixed sleep apneas in 1,023 infants. Sleep 2000;23:487-492.

68. Mulvaney SA, Goodwin JL, Morgan WJ, Rosen GR, Quan SF, Kaemingk KL. Behavior problems associated with sleep disordered breathing in school-aged children:-the Tucson Children's Assessment of Sleep Apnea Study. J Pediatr Psychol 2006;31:322-330.

69. Chng SY, Goh DY, Wang XS, Tan TN, Ong NB. Snoring and atopic disease: a strong association. Pediatr Pulmonol 2004;38:210-216.

70. Owens JA, Maxim R, Nobile C, McGuinn M, Msall M. Parental and selfreport of sleep in children with attention-deficit/hyperactivity disorder. Arch Pediatr Adolesc Med 2000;154:549-555.

71. Shin C, Joo S, Kim J, Kim T. Prevalence and correlates of habitual snoring in high school students. Chest 2003;124:1709-1715.

72. Visscher TLS, Viet AL, Kroesbergen HT, Seidell JC. Underreporting of BMI in adults and its effect on obesity prevalence estimations in the period 1998 to 2001. Obesity (Silver Spring) 2006;14:2054-2063.

73. Hill A, Roberts J. Body mass index: a comparison between self-reported and measured height and weight. $J$ Publ Health 2006;20:206-210.

74. Morrissey SL, Whetstone LM, Cummings DM, Owen LJ. Comparison of self-reported and measured height and weight in eighth-grade students. J Sch Health 2006;76:512-515.

75. Brener ND, McManus T, Galuska DA, Lowry R, Wechsler H. Reliabilty and validity of self-reported height and weight among high school students. J Adolesc Health 2003;32:281-287.

76. Huybrechts I, Debacquer D, VanTrimpont I, DeBacker G, DeHanauw S. Validity of parentally reported weight and height for preschoolaged children in Belgium and its impact on classification into body mass index categories. Pediatrics 2006;118:2109-2118.

77. Ogden CL, Flegal KM, Carroll MD, Johnson CL. Prevalence and trends in overweight among US children and adolescents, 1999-2000. JAMA 2002;288:1728-1732.

78. Marcus CL, Hamer A, Loughlin GM. Natural history of primary snoring in children. Pediatr Pulmonol 1998;26:6-11.

79. Topol HI, Brooks LJ. Follow-up of primary snoring in children. J Pediatr 2001;138:291-293.

80. Urschitz MS, Guenther A, Eitner S, Urschitz-Duprat PM, Schlaud M, Ipsiroglu OS, Poets CF. Risk factors and natural history of habitual snoring. Chest 2004;126:790-800.

81. Chervin RD, Ruzicka DL, Archbold KH, Dillon JE. Snoring predicts hyperactivity four years later. Sleep 2005;8:885-890.

82. Chervin RD, Archbold KH, Panahi P, Pituch KH. Sleep problems seldom addressed at two general pediatric clinics. Pediatrics 2001;107:1375-1380.

83. Kara CO, Ergin H, Kocak G, Kilic I, Yurdakul M. Prevalence of tonsillar hypertrophy and associated oropharyngeal symptoms in primary school children in Denizli, Turkey. Int J Pediatr Otorhinolaryngol 2002;66:175-179.

84. Stradling JR, Thomas G, Warley ARH, Williams P, Freeland A. Effect of adenotonsillectomy on nocturnal hypoxaemia, sleep disturbance, and symptoms of snoring children. Lancet 1990;335:249-253.

85. Muzumdar H, Arens R. Diagnostic issues in pediatric obstructive sleep apnea. Proc Am Thorac Soc 2007;5:263-273. 